\title{
Modeling car-sharing membership as a mobility tool A multivariate Probit approach with latent variables
}

\author{
Journal Article \\ Author(s): \\ Becker, Henrik; Loder, Allister; Schmid, Basil; Axhausen, Kay W. (D) \\ Publication date: \\ 2017-07 \\ Permanent link: \\ https://doi.org/10.3929/ethz-b-000130360 \\ Rights / license: \\ In Copyright - Non-Commercial Use Permitted \\ Originally published in: \\ Travel Behaviour and Society 8, https://doi.org/10.1016/j.tbs.2017.04.006
}




\title{
Modeling car-sharing membership as a mobility tool: A multivariate Probit approach with latent variables
}

\author{
Henrik Becker ${ }^{\mathrm{a}, *}$, Allister Loder $^{\mathrm{a}}$, Basil Schmid $^{\mathrm{a}}$, Kay W. Axhausen ${ }^{\mathrm{a}}$ \\ ${ }^{a}$ ETH Zurich, Institute for Transport Planning and Systems, Stefano-Franscini-Platz 5, \\ 8093 Zurich, Switzerland
}

\begin{abstract}
Individual travel behavior is to a large extent shaped by the respective portfolio of available mobility tools such as cars, season-tickets or a car-sharing membership. However, the choices of different mobility tools are interdependent and are also affected by individual attitudes. This paper presents an approach to jointly model the choice of four different mobility tools - including car-sharing. Using data from the Swiss transportation micro census of 2005 and 2010, it is shown that car-sharing is used as a supplement to a public transportationoriented lifestyle, but is also used by car owners. The results further indicate that personal attitudes have a substantial effect on the choice of mobility tools and should therefore be accounted for when modeling such decisions.
\end{abstract}

Keywords: car-ownership, car-sharing, season ticket, mobility tool, multivariate probit, attitudes, latent variables

*Corresponding author
Email address: henrik.becker@ivt.baug.ethz.ch (Henrik Becker)

Preprint submitted to Travel Behaviour and Society

April 13, 2017 


\section{Introduction}

Arranging one's individual transportation requires various choices at different levels, of which many are interdependent. In particular, the strategic decision to own a certain mobility tool, e.g. a car, largely determines the later 5 tactical decisions on mode choice and therefore shapes individual travel behavior [1. Yet, interdependencies do not only occur between the different levels of transportation choices, but also within them. For example, it has been shown that car owners are less prone to subscribe to a season ticket [2], whereas seasonticket holders in turn may be more likely to become car-sharing members [3]. In this analysis, it is assumed that the choices on mobility tools are made simultaneously. As such multiple choices may share common underlying unobserved factors and one outcome might be an endogenous factor in another outcome, jointly modeling multiple outcomes accounts for interdependencies and provides deeper insights into the decision making process [4, 5, 6, 7.

For a long time, (motor-)bikes, private vehicles and public transportation subscriptions were the only relevant mobility tools. However, in the recent years, car-sharing was established as additional option providing their members with short-term access to vehicles on an as-needed basis. The schemes attract both scientific interest and customers around the world 8 .

The literature suggests that station-based car-sharing reduces private vehicle ownership as well as vehicle kilometers travelled [9, 10, 11, although there has been less agreement on the magnitude of this impact [12. Moreover, previous research has consistently revealed that car-sharing schemes blossom best in dense urban areas with a good public transportation supply and mainly attract young, highly-educated, higher-income, urban, car-free and single-household residents [13, 14, 3]. 
counted for the apparent causal interrelation and jointness of car-sharing membership with the ownership of other mobility tools [15. Instead, the level of car-ownership or the availability of season tickets usually were used as possibly endogenous explanatory variables when modeling car-sharing membership.

35 This however disregards that all three are (simultaneous) outcomes of the same underlying decision process on a portfolio of mobility tools.

Another limitation is that most previous research on factors influencing carsharing membership has mainly focused on socio-demographic factors ignoring the role individual attitudes and lifestyles play in such decisions [16, 17.

This study presents an approach to model car-sharing membership as part of a portfolio of mobility tools allowing to account for both the interdependencies with other mobility tools as well as the effect of individual attitudes on car45 sharing membership. In particular, the approach is supposed to shed new light on travelers' actual motivations to become car-sharing members and help to better understand the actual role, car-sharing plays in its members' travel behavior.

The remainder of this paper is structured as follows: Section 2 provides an introduction to both car-sharing and recent advances in modeling mobility tool ownership. In Section 3, the dataset used for this analysis is described. Section 4 then describes the incorporation of attitudes into the analysis, while Section 5 presents the modeling framework used for this research. In Section 6, the model results are presented. Finally, Section 7 provides a discussion of the insights 55 gained by this analysis. 


\section{Background}

\subsection{Mobility tools in Switzerland}

In this research, a mobility tool is defined as an item which after a substantial down-payment provides permanent access to a certain mode of mobility 60 at low or zero marginal cost for a time-span of at least one year. Typically, Swiss residents have the choice between four such mobility tools: a car, a local season ticket, a nation-wide season ticket (GA travelcard) and a car-sharing membership. Following the definition from above, bikes and motorbikes have been omitted in this list given that they usually do not present a substantial (yearly) investment and are usually not used in all of the four seasons.

In Switzerland, the most common mobility tool is the private car. It represents an average yearly investment of CHF 6600 (average annual gross income per household: $121000 \mathrm{CHF}^{1}$ 1.00 $\mathrm{CHF}=0.70 \mathrm{USD}^{2}$ and subsequently allows inexpensive and flexible mobility at an average of CHF $0.27 / \mathrm{km}^{3}$ However, given the particularly well-developed network, public transportation in many cases is a competitive alternative to cars and in some (i.e. travel between the larger cities), it is even superior. While a GA travelcard allows for unlimited travel within the entire public transport network throughout the country, a local 75 season ticket provides access to public transportation within a defined zone or corridor. A GA travelcard has a cost similar to a car: It requires a substantial fixed investment of CHF 3655 (2nd class) or CHF 5970 (1st class) per year for the first family member followed by almost no marginal costs. Discounts for

\footnotetext{
${ }^{1}$ according to household budget survey 2014: https://www.bfs.admin.ch/bfs/en/ home/statistics/economic-social-situation-population/income-consumption-wealth/ household-budget.html

${ }^{2}$ at 2015 purchasing power parity for private consumption according to OECD (2015): http://stats.oecd.org/Index.aspx?datasetcode=SNA_TABLE4

https://www.tcs.ch/de/auto-zweirad/auto-kaufen-verkaufen/

auto-unterhaltskosten/kosten-eines-musterautos.php

${ }^{4}$ prices as of 2015
} 
additional family members apply. The least expensive option are local season tickets starting at around CHF 700 per year.

The fourth option is a membership of the national car-sharing operator, which provides access to vehicles at almost 1500 car-sharing stations throughout the country. Dating back to 1987, this station-based car-sharing scheme presents an interesting case, because it is available not only in larger cities, but also in smaller towns and villages. Therefore, it is probably the only scheme worldwide offering a seamless system covering an entire country. It offers its 127000 members access to almost 3000 vehicles of various types at 1500 car-sharing stations (often located at train stations or other central areas) 5 . Members can either: 90 buy a share of the cooperative (one-time investment of $1250 \mathrm{CHF}$ of which $1000 \mathrm{CHF}$ is refundable upon exit), or subscribe to the service for an annual fee of 200 to 300 CHF. The membership fee can be substantially reduced to CHF 25 for holders of a public transportation subscription, although these members pay higher rental fees. Rentals are charged both by the hour and by distance travelled (currently 3 to $4 \mathrm{CHF} / \mathrm{h}$ plus 0.50 to $1.00 \mathrm{CHF} / \mathrm{km}$, depending on the vehicle type and time of the day).

Table 1 presents the distribution of ownership of the four mobility tools. It already indicates that car-ownership and public transportation subscriptions are 100 substitutes. While car-sharing is overrepresented among holders of PT subscriptions and underrepresented among car-owners, car-sharing members are highly equipped with mobility tools, in particular GA travelcards. Also, their level of car-ownership is slightly higher than the one of holders of a PT subscription.

\footnotetext{
${ }^{5}$ according to the Mobility Cooperative's business report for the year 2015: https://www.mobility.ch/en/about-mobility/mobility-cooperative/about-us/ company-reports/
} 
Table 1: Swiss distribution of mobility tool ownership based on micro census mobility and transportation ( $N=8477$ - including respondents over 18 years of age and including respondents without drivers license) [18, 19.

\begin{tabular}{l|rrrr}
\hline & Car & PT subscription & GA travelcard & Car-sharing \\
\hline$n$ & 5581 & 1935 & 736 & 199 \\
Base-rate & $65.8 \%$ & $22.8 \%$ & $8.7 \%$ & $2.4 \%$ \\
\hline Subsets & & & & \\
Car-owners & & $13.0 \%$ & $3.6 \%$ & $1.4 \%$ \\
PT subscription holders & $37.5 \%$ & & $38.0 \%$ & $5.0 \%$ \\
GA travelcard holders & $34.8 \%$ & & & $7.1 \%$ \\
Car-sharing members & $40.2 \%$ & $48.7 \%$ & $26.1 \%$ & \\
\hline
\end{tabular}

\subsection{Car-Sharing}

members, although those motivations were not cross-referenced to their respective socio-demographic background. Such surveys have been conducted in various (mostly industrialized) countries around the globe and consistently found 
that car-sharing is particularly attractive to 25-45 year olds of higher educa-

Therefore, the actual role of car-sharing in a portfolio of mobility tools is still largely unclear. This research aims at filling this gap by studying the causal 
In contrast, in the multivariate Probit approach, multiple correlated binary choice outcomes are modeled simultaneously, allowing to account for correlations in the error terms between the individual choice outcomes [34] rather than explicitly modeling each combination of choice outcomes as in the multinomial 
185

date mixed types of outcomes, e.g. multinomial or ordered outcomes, in which common unobserved factors and endogeneity might be present [6]. The multivariate Probit also allows to accommodate truncated samples [35, 36] as well as spatial and social interaction [7].

190

Various studies have made use of the multivariate Probit approach in transportation. For example, 29] applied the trivariate Probit model to describe car, motorcycle and bicycle ownership in Osaka and Kuala Lumpur, whereas [37] use it to study choices of shopping channels for clothing purchases. In addition, the bivariate ordered Probit model was used for model the number of different mobility tools at the household level, e.g. car and motorcycle ownership [38, 39] or car and season ticket ownership [30]. [40] also used a bivariate ordered Probit model to study the frequency of use of car-sharing and ridesourcing services. All studies mentioned above found significant correlations 200 across choice outcomes meaning that common unobserved factors are at work. The research presented in this paper builds upon this earlier research and uses a multivariate Probit approach to jointly model the ownership of different kinds of mobility tools. 


\section{Data}

205

210

3.1. Swiss transportation micro census

This research is based on data from the Swiss national travel surveys (micro census) of 2005 and 2010 [18, 19]. The micro census is a quint-annual national CATI survey covering a substantial share of the Swiss population. It provides detailed information on household demographics as well as socio-economic information and travel patterns on the individual level for at least one household member. A share of the respondents was further asked policy questions allowing to infer individual transport policy attitudes. Table 2 presents the size of the available datasets. The micro census covers persons older than 6 years. However, for this analysis, only respondents above legal and car driving age (18 years) are considered.

In the micro census, the season-ticket ownership and car-sharing membership are captured on the individual level. While the car-sharing question is a simple yes/no-question, various types of public transport subscriptions are available. (Verbundabo) and a corridor-based season-ticket (Streckenabo) were counted as public transport subscriptions. All other options (including the half fare discount card) were neglected since they neither represent a substantial investment nor do they allow free travel in any area.

225

Car-ownership information is captured by two questions: On the household level, there is a question asking for the number of cars registered in the household (numeric), and on the individual level, there is a question asking whether the respondent had access to a car (levels: always, upon consultation, never). Given its more direct effect on travel decisions, the latter variable was used in this analysis. This is in contrast to the recommendation by 28 , to use the number of cars at household level, because the micro census captures disaggregate information on individual mobility tool availability for only one household mem- 
ber. A car was assumed an available mobility tool if it was always available,

the option upon consultation was counted as unavailable.

Table 2: Number of observations in the micro census.

\begin{tabular}{l|rr}
\hline Year & 2005 & 2010 \\
\hline Respondents & 28785 & 55060 \\
Respondents with transport policy attitude items & 3644 & 5239 \\
\hline
\end{tabular}

\subsection{Data enrichment}

Although the micro census contains many variables of interest, some additional variables were constructed because they were expected to have a substantial impact on mobility tool ownership.

In a first step, some of those variables included in the 2010 data, but missing in the 2005 data were added to the 2005 data. This concerns mainly the level of service (micro-accessibility) of public transportation ${ }^{6}$ at the individual home location as well as the spatial structure at the given work place. In a second step, variables missing in both data sets were added. In particular, municipal accessibility scores (for both car and public transportation) of the individual home locations were obtained from [42. The accessibility scores were then decomposed into three principal components describing general accessibility, comparative higher accessibility of public transportation and the comparative higher accessibility to work places [43. In addition, the distance to the closest car-sharing station was calculated using the individual household coordinates and the station locations of the national car-sharing provider Mobility [44].

\footnotetext{
${ }^{6}$ The level of service was assigned based on the individual household coordinates from the micro census and a shape file with the level of service zones provided by 41 . The classification of the spatial structure was conducted based on the (available) workplace municipality code. The information was then passed through from the available information on municipality code and spatial structure from the home locations in the micro census.
} 
Similar to other studies, also the micro census suffers from substantial itemnonresponse at the household income question (2005: 20\%; 2010: 17\%). However, since this variable is an important predictor in most car-ownership models, it was imputed using an ordered Logit approach 7

\footnotetext{
${ }^{7}$ Eventually, for only 36 observations, the household income remained missing. Detailed information on the imputation procedure and the OL model estimates are available from the corresponding author upon request.
} 


\section{Attitudes}

\subsection{Data and factor structure}

The micro census data used for this research [18, 19] also contain selfreported attitudes towards transport policies, e.g. different forms of mobility pricing and infrastructure investments. Responses to attitudinal questions are coded in an asymmetric 3 -point Likert-scale $(1=$ disagree; $2=$ potentially agree; $3=$ agree). For this research, latent constructs are calculated based on those questions included in both the 2005 and the 2010 data set.

Table 3 presents the items available for the analysis. As shown in the table, there is substantial item-nonresponse leading to a final sample size of 6952 observations (of 8883 ) without imputation. However, given the strong cross-correlations of certain items and the predictive power of exogenous socio-economic characteristics, an efficient imputation algorithm was implemented to maximize the available sample size (8488 observations remain).

An exploratory factor analysis was conducted to reduce the data to the most essential elements and to determine the latent constructs (number of latent variables) for the subsequent analysis. Based on the factor-Eigenvalue plot, the results of a parallel analysis and the latent-root-criterion [45, two latent variables consisting of highly related items were retained, explaining the most important dimensions of variability. The factor loadings as reported in Table 3 can be interpreted as correlations between the factor and corresponding items. A higher factor loading (in absolute value) means that the respective item is more representative of the factor. As shown in Table 3, the resulting factor structure is meaningful and statistically robust (acceptable goodness-of-fit measures for factor reliability and correlation structure). The two retained factors may be described as follows:

- PROFEES: The PROFEES factor (F1) exhibits high positive loadings on items demanding the introduction or increase of road traffic fees (tunnel, 
Table 3: Attitudes and factor analysis (before imputation): Pricing schemes and infrastructure improvements.

\begin{tabular}{|c|c|c|c|c|c|c|}
\hline Questionnaire item & Obs. & Mean & $\mathrm{SD}$ & NA's & Factor F1 & Factor F2 \\
\hline PHF: Introduction of peak hour fees & 8142 & 2.40 & 0.85 & 741 & +0.55 & - \\
\hline PF: Increase in parking fees & 8198 & 2.55 & 0.78 & 685 & +0.64 & - \\
\hline FP: Increase in fuel price & 8334 & 2.65 & 0.70 & 549 & +0.63 & - \\
\hline RPT: Road traffic revenues for PT infrastructure & 8302 & 1.48 & 0.77 & 581 & - & +0.47 \\
\hline RR: Road traffic rev. for road infrastructure & 8303 & 1.37 & 0.69 & 580 & -0.30 & - \\
\hline RSM: Road traffic rev. for slow mode infra. & 8445 & 1.29 & 0.63 & 438 & - & +0.57 \\
\hline REN: Road traffic rev. for environment & 8388 & 1.32 & 0.65 & 495 & - & +0.56 \\
\hline
\end{tabular}

Estimation method: Maximum likelihood Rotation method: Orthogonal varimax Variance explained: $62.0 \%$. Cronbach's Alpha: 0.63 Kaiser-Meyer-Olkin measure of sampling adequacy: 0.75

peak hour, parking and fuel) and not spending the revenues of such fees on the road infrastructure,

- PROINFRA: The PROINFRA factor (F2) shows positive loadings on items reflecting an inclination towards spending revenues from car fees on investments in infrastructure for public transportation and slow modes (walk and bike) or environmental protection projects.

Table 4 contains some basic summary statistics of the socio-demographic variables for $\mathrm{N}=8488$ respondents (no missing values) that are found to affect the attitudes, i.e. the factor scores of PROFEES and PROINFRA, the strongest. The socio-demographic attributes were identified using a simple correlation analysis.

\subsection{MIMIC model to predict latent variables}

This subsection presents the methods used to calculate the latent variables, i.e. the attitudes towards pricing schemes and infrastructure investments, which 
Table 4: Socio-economic characteristics used.

\begin{tabular}{l|rrrr} 
Questionnaire item & Mean & SD & Min. & Max. \\
\hline HHSIZE: Household size & 2.36 & 1.31 & 1 & 10 \\
HHINC: Household income [1000 CHF] & 6.96 & 4.02 & 1.5 & 20 \\
HHBIKES: Number of bikes in household & 1.79 & 1.79 & 0 & 20 \\
MALE: Gender [male = 1] & 0.46 & 0.50 & 0 & 1 \\
AGE: Age [years] & 50.74 & 17.68 & 18 & 97 \\
EDUC: Educ. level [above apprenticeship =1] & 0.63 & 0.48 & 0 & 1 \\
LIC: Car driving license [yes = 1] & 0.82 & 0.39 & 0 & 1 \\
CITY: Residential location [city = 1] & 0.32 & 0.47 & 0 & 1 \\
TICKET: Public transport subscription [yes $=1]$ & 0.23 & 0.41 & 0 & 1 \\
FULLTIME: Working $\geq 36$ h/week [yes $=1]$ & 0.58 & 0.49 & 0 & 1 \\
PARTTIME: Working $<36$ h/week [yes $=1]$ & 0.12 & 0.33 & 0 & 1 \\
GER: Home in Swiss-German region [yes $=1]$ & 0.67 & 0.47 & 0 & 1 \\
FRE: Home in Swiss-Romand region [yes $=1]$ & 0.27 & 0.45 & 0 & 1 \\
ITA: Home in Swiss-Italian region [yes $=1]$ & 0.06 & 0.23 & 0 & 1 \\
\hline
\end{tabular}

are later used as explanatory variables to better describe the choice of different mobility tools. Although this sequential estimation approach is neither efficient nor consistent [46, 47, its has often shown identical qualitative implications as in a simultaneous estimation approach [48].

The modeling strategy followed in this research is to first predict the two latent variables ("first-step" predictions) for the full sample, a method that relies on the rather strong assumptions of joint normality and values missing at random (or the weaker assumption of covariate-dependent missingness; 49]) 8 These "first-step" predictions are then used to impute the missing values by estimating Ordered Logit (OL) models with the attitudinal items as dependent variables.

\footnotetext{
${ }^{8}$ The test for joint normality of items $\left(H_{0}\right)$ was rejected. However, the test for covariatedependent missingness $\left(H_{0}\right)$ of items was accepted. The modeling approach is similar to the one shown in Equations 1-4, but assumes linear instead of Ordered Logit measurement equations, which is necessary to apply the maximum likelihood with missing values approach [50]. This procedure helps to overcome the case-wise deletion of rows containing missing values.
} 
The OL approach has the main advantage that it accounts for discrete nature of the items (3-point Likert-scales) which also are asymmetric (i.e. given the second category "potentially agree"), for which a linear measurement model would be inadequate [51]. Given that the "first-step" predictions have a high explanatory power (they are, of course, highly correlated with the corresponding items) and that only very few items of a specific respondent are missing, the imputation strategy can be assumed to be reasonably accurate.

Based on the factor structure and corresponding items from above, for both latent variables in Table 4, a multiple-indicator-multiple-cause (MIMIC) 52. structural equation model (SEM) [53, 54] was estimated. This was done by simultaneously modeling an OL measurement equation linking the latent variables with the items assumed to affect the latent constructs and a linear structural equation for the exogenous variables affecting the latent variables. Once the coefficients are estimated, they can be applied to predict the distribution of attitudes for a population of interest.

The measurement equation for latent variable $i \in\{$ PROFEES,PROINFRA $\}$ with responses of individual $n$ to the questionnaire items $I_{a t t}$ is given by:

$$
\begin{gathered}
P\left(I_{a t t, n}=1\right)=\frac{1}{1+\exp \left(-\kappa_{a t t, 1}+\tau_{I_{a t t}} L V_{i, n}\right)} \\
P\left(I_{a t t, n}=2\right)=\frac{1}{1+\exp \left(-\kappa_{a t t, 2}+\tau_{I_{a t t}} L V_{i, n}\right)}-\frac{1}{1+\exp \left(-\kappa_{a t t, 1}+\tau_{I_{a t t}} L V_{i, n}\right)}(2) \\
P\left(I_{a t t, n}=3\right)=1-\frac{1}{1+\exp \left(-\kappa_{a t t, 2}+\tau_{I_{a t t}} L V_{i, n}\right)}
\end{gathered}
$$

where $\tau_{I_{a t t}}$ are the latent variable coefficients for each item $I_{a t t}$ (note: for identification reasons, $\tau_{I_{a t t}}$ for TF (PROFEES) and for RPT (PROINFRA) are fixed at 1$), L V_{i, n}$ are the latent variables and $\kappa_{a t t_{i}}$ are cutoff values for each item. The structural equation for latent variable $i$ is a function of observed socio-economic characteristics $Z_{n}$ :

$$
L V_{i, n}=Z_{i, n} \kappa_{i}+\omega_{L V_{i, n}}
$$


where $Z_{i, n}$ is a $1 \times$ x $q$ vector of socio-economic characteristics, $\kappa_{i}$ is a $q$ x 1 coefficient vector and $\omega_{L V_{i, n}}$ is a $n \times 1$ random disturbance vector.

Table 5 presents the results of the MIMIC model. The results of the measurement model as given in the top rows confirm the findings of the factor analysis shown in Table 3 . For PROFEES, increasing fuel and parking prices (FP, PF) exhibit the strongest effect on the latent variable, whereas road revenues for road infrastructure improvements (RR) show the weakest (and negative) effect. For PROINFRA, spending road revenues on environmental protection (REN) exhibits the strongest effect. The effects of socio-economic characteristics on the latent variables are presented in the bottom rows. The model shows that increasing PROFEES attitudes are mainly affected by lower household size, increasing age, higher income and education, the number of bikes, season ticket ownership and living in the German-speaking part of the country. Increasing PROINFRA attitudes are mainly affected by being male, a lower household income, higher education, the number of bikes, season travelcard ownership and an urban home location. Finally, the correlation between PROFEES and PROINFRA of about $0.17(p<0.00)$ is moderate and plausible: infrastructure and environmental protection expenses have to be funded somehow and fees on car use may be regarded as a possible way to generate the necessary funds. 
Table 5: MIMIC model results $(\mathrm{N}=8488)$. Variable codes as defined in Tables 3 and 4

\begin{tabular}{|c|c|c|c|}
\hline & & & PROINFRA \\
\hline Variable & Coef./(SE) & Variable & Coef./(SE) \\
\hline $\mathrm{TF}$ & 1 & $\mathrm{RPT}$ & 1 \\
\hline PHF & $1.468^{* * *}$ & RSM & $1.339^{* * *}$ \\
\hline $\mathrm{PF}$ & $2.207^{* * *}$ & REM & $1.793^{* * *}$ \\
\hline FP & $2.255^{* * *}$ & - & - \\
\hline PFS & $1.183^{* * *}$ & - & - \\
\hline $\mathrm{RR}$ & $-0.580^{* * *}$ & - & - \\
\hline HHSIZE & $-0.101 * * *$ & - & - \\
\hline AGE & $0.007^{* * *}$ & AGE & $-0.005^{* * *}$ \\
\hline MALE & $-0.117^{* * *}$ & MALE & $-0.429^{* * *}$ \\
\hline HHINC & $0.018^{* * *}$ & HHINC & $-0.022^{* * *}$ \\
\hline EDUC & $0.222^{* * *}$ & EDUC & $0.139^{* *}$ \\
\hline CITY & $0.254^{* * *}$ & CITY & $0.184^{* * *}$ \\
\hline HHBIKES & $0.100^{* * *}$ & HHBIKES & $0.057^{* * *}$ \\
\hline PARTTIME & $0.209^{* * *}$ & FULLTIME & $-0.201^{* * *}$ \\
\hline GER & $0.447^{* * *}$ & GER & $-0.871^{* * *}$ \\
\hline- & - & FRE & $-0.509^{* * *}$ \\
\hline$\sigma_{L 1}^{2}$ & $0.906^{* * *}$ & $\sigma_{L 2}^{2}$ & $1.416^{* * *}$ \\
\hline \multicolumn{4}{|c|}{${ }^{* * *} p<0.001,{ }^{* *} p<0.01,{ }^{*} p<0.05$} \\
\hline \multicolumn{4}{|c|}{ Note: Cutvalues $\kappa_{a t t_{i}}$ not reported. } \\
\hline
\end{tabular}




\section{Model Formulation}

360 distribution of mobility tools for this subsample is presented in Table 10 Although dropping observations without drivers license may bias the general distribution of mobility tool ownership, we argue that car-sharing as a mobility tool is unavailable to non-license holders. Therefore, modeling car-sharing as mobillicense holders as censored observations and treat them in a sample selection approach 55. However, this approach was not pursued given that the correlation of the error terms $\rho$ between the main regression (on car availability) and selection equation (on drivers license holding) is not significantly different from

Of the four mobility tools, the two season tickets are direct substitutes. Hence, modeling all four outcomes within a four-dimensional multivariate Probit approach could indicate that both mobility tools are substitutes, but would not holding a season ticket. Therefore, the model takes the form of a multivariate Probit model with sample selection, a Probit extension of the [55] model for truncated samples. Both the multivariate Probit, e.g. [6, 29, 30, and the pro- 
bit with sample selection, e.g. [35, 36, 56], are well-established methodologies. Also the bivariate probit with endogenious treatment is widely used in some disciplines [57, 58, 59, 60] and has recently been extended by Bhat and his colleagues to model mixed types of outcomes [61, 6].

In this research, it is assumed that Swiss residents have four choices as presented in Table 6. In the multivariate Probit formulation, each of the four choices is modeled by one equation as given in the right column in Table $6 . Y_{i}^{*}$ is the latent propensity associated with choice $i$. In case $Y_{i}^{*}>0$, the outcome is chosen, i.e. the individual owns the respective mobility tool. $x_{i}$ is a vector of observed covariates and $\beta_{i}$ a vector of coefficients to be estimated. $\varepsilon_{i}$ is the error term.

Yet, the interest is not in modeling the individual choice outcomes, but Table 6: Model equations

\begin{tabular}{cll}
\hline Number & Choice & Equation \\
\hline 1 & Car & $Y_{1}^{*}=\beta_{1} x_{1}+\varepsilon_{1}$ \\
2 & Car sharing memebership & $Y_{2}^{*}=\beta_{2} x_{2}+\varepsilon_{2}$ \\
3 & Any Season ticket & $Y_{3}^{*}=\beta_{3} x_{3}+\varepsilon_{3}$ \\
4 & GA $\left(Y_{4}=1\right)$ or local season ticket $\left(Y_{4}=0\right)$ & $Y_{4}^{*}=\beta_{4} x_{4}+\varepsilon_{4}$ \\
\hline
\end{tabular}

their combination. The 12 possible outcome combinations are given in Table 7 The probability of each outcome combination is calculated by evaluating the $n$ dimensional multivariate cumulative density function of the normal distribution $\Phi_{n}$ at the point defined by the $n$-dimensional vector housing the latent propensities $Y_{i}^{*}$ and the $n$-dimensional correlation matrix $\Sigma_{n}$. The correlations in $\Sigma$ are informative, because a negative correlation indicates that both outcomes are substitutes, whereas a positive correlation corresponds to complements. The sample selection can be ignored if $\rho_{34}$ is not significantly different from zero. If none of the correlations are significant, no joint modeling is required. 
The vectors $\beta_{1}$ to $\beta_{4}$ and the entries of the correlation matrix $\Sigma_{4}$ are the

Table 7: Outcome combinations and their probabilities for car, car-sharing membership, local season ticket (LST) and GA travelcard (GA).

\begin{tabular}{cllr}
\hline Number & Outcome combination & Probability & Share in obs. [\%] \\
\hline 1 & None & $P_{1}=\Phi_{3}\left(-\beta_{1} x_{1},-\beta_{2} x_{2},-\beta_{3} x_{3} ; \Sigma_{3}\right)$ & $11.1 \%$ \\
2 & Car & $P_{2}=\Phi_{3}\left(\beta_{1} x_{1},-\beta_{2} x_{2},-\beta_{3} x_{3} ; \Sigma_{3}\right)$ & $69.2 \%$ \\
3 & Car-sharing member & $P_{3}=\Phi_{3}\left(-\beta_{1} x_{1}, \beta_{2} x_{2},-\beta_{3} x_{3} ; \Sigma_{3}\right)$ & $0.7 \%$ \\
4 & Car and car-sharing member & $P_{4}=\Phi_{3}\left(\beta_{1} x_{1}, \beta_{2} x_{2},-\beta_{3} x_{3} ; \Sigma_{3}\right)$ & $0.8 \%$ \\
5 & LST & $P_{5}=\Phi_{4}\left(-\beta_{1} x_{1},-\beta_{2} x_{2}, \beta_{3} x_{3},-\beta_{4} x_{4} ; \Sigma_{4}\right)$ & $3.9 \%$ \\
6 & LST and car & $P_{6}=\Phi_{4}\left(\beta_{1} x_{1},-\beta_{2} x_{2}, \beta_{3} x_{3},-\beta_{4} x_{4} ; \Sigma_{4}\right)$ & $6.6 \%$ \\
7 & LST and car sharing member & $P_{7}=\Phi_{4}\left(-\beta_{1} x_{1}, \beta_{2} x_{2}, \beta_{3} x_{3},-\beta_{4} x_{4} ; \Sigma_{4}\right)$ & $0.5 \%$ \\
8 & LST, car and car sharing member & $P_{8}=\Phi_{4}\left(\beta_{1} x_{1}, \beta_{2} x_{2}, \beta_{3} x_{3},-\beta_{4} x_{4} ; \Sigma_{4}\right)$ & $0.2 \%$ \\
9 & GA & $P_{9}=\Phi_{4}\left(-\beta_{1} x_{1},-\beta_{2} x_{2}, \beta_{3} x_{3}, \beta_{4} x_{4} ; \Sigma_{4}\right)$ & $2.9 \%$ \\
10 & GA and car & $P_{10}=\Phi_{4}\left(\beta_{1} x_{1},-\beta_{2} x_{2}, \beta_{3} x_{3}, \beta_{4} x_{4} ; \Sigma_{4}\right)$ & $3.5 \%$ \\
11 & GA and car-sharing member & $P_{11}=\Phi_{4}\left(-\beta_{1} x_{1}, \beta_{2} x_{2}, \beta_{3} x_{3}, \beta_{4} x_{4} ; \Sigma_{4}\right)$ & $0.6 \%$ \\
12 & GA, car and car-sharing member & $P_{12}=\Phi_{4}\left(\beta_{1} x_{1}, \beta_{2} x_{2}, \beta_{3} x_{3}, \beta_{4} x_{4} ; \Sigma_{4}\right)$ & $0.2 \%$ \\
\hline
\end{tabular}

coefficients to be estimated. All parameters are estimated by maximum simulated likelihood [62]. The associated log-likelihood function is defined as the sum over all $N$ individuals' chosen outcome combination probabilities $P$ :

$$
\log \left(\mathcal{L}\left(\beta, \Sigma_{4}\right)\right)=\sum_{i=1}^{N} \sum_{j=1}^{12} \delta_{i j} \log \left(P_{i j}\right)
$$

where $\delta_{i j}$ is an indicator variable for observation $i$ and outcome combination $j$. The entries of the correlation matrix $\Sigma_{4}$ are not estimated directly. Instead, the Cholesky factors resulting from the associated Cholesky decomposition of $\Sigma_{4}$ are used. The requirements for model identification follow common procedure, but the interested reader is directed to the work by [6] and 62 for a more detailed discussion. Maximum simulated likelihood estimators are consistent, asymptotically normal, and efficient if the number of draws approaches infinity faster than the square root of the number of observations [63. For model 
425 estimation in Stata 9 the built-in option of robust standard errors was chosen.

${ }^{9}$ The code is available upon request. 


\section{Results}

Following the methodology outlined above, the ownership of the four mobility tools was modeled jointly. In order to obtain the best model fit, various combinations of covariates were tested iteratively using subsamples of the data. The final model was estimated based on the complete data set (micro census 2005 and 2010, adult respondents with the attititudes-module only) using 250 random draws. Table 8 presents the results both for the multivariate Probit model and for individual univariate Probit models for comparison. However, given that Table 9 indicates significant correlations, only the results of the joint model are used for interpretation.

As shown in the table, there are significant differences between the results of the two modeling approaches, in particular in the effects of accessibility, spatial structure and the latent variables on GA travelcard holdings. Hence, using a multivariate modeling approach helps to better determine the effects of the explanatory variables. Judging from the pseudo $R^{2}$, the univariate models achieve an explanatory power comparable to earlier studies in Switzerland [31, whereas the joint modeling approach achieves a higher explanatory power. Moreover, it is important to note that excluding respondents without a drivers license does not change the results substantially (cf. Table 11).

The model was estimated based on a pooled data set of the two micro census. This is justified by the fact that both the survey method as well as the target group (representative sample of the Swiss population) were the same. To capture general trends in mobility tool ownership, an indicator variable was included to identify observations from the later data set (2010). As shown in Table 8 , the results indicate a substantial trend towards more season ticket ownership. 


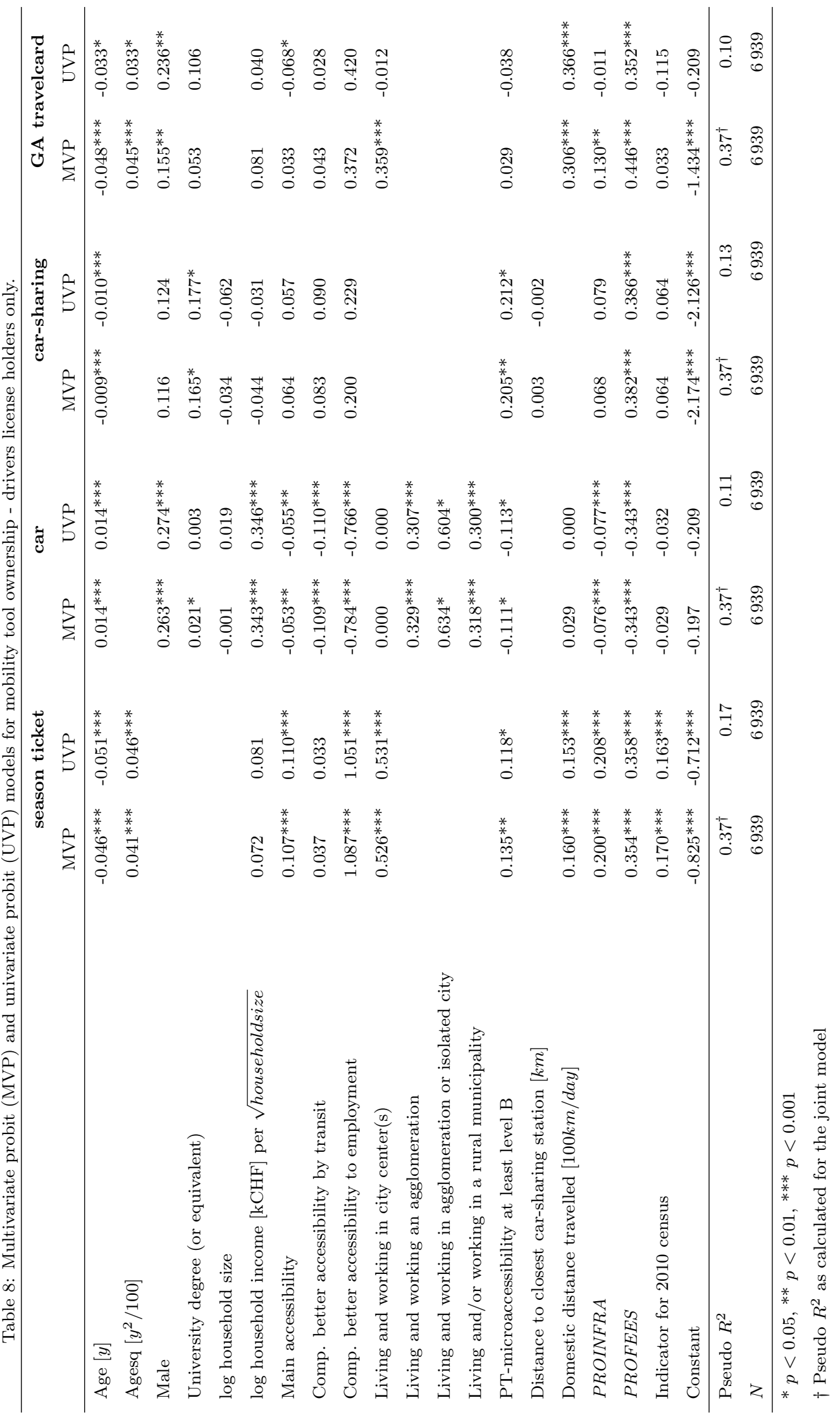


are used. For example, as shown in the four models, accessibility to both population and employment has a substantial impact on the choice of mobility tools. The better a place is accessible, the less likely households are to own a car. In turn, residents of such areas own more season tickets for public transportation. The micro-accessibility of public transportation affects the choice of mobility tools in a similar way: Living in an area with a high micro-accessibility ${ }^{10}$ (i.e. levels A or B) substantially increases the propensity to hold season tickets and car-sharing memberships. With respect to car-sharing, it is interesting to note that only the effect of the micro-accessibility of public transportation is significant, whereas the effect of accessibility is insignificant. In addition, the results show that people who both live and work in a city are more likely to hold a local season ticket or a GA travelcard.

Furthermore, the model shows that a higher household income per capita in470 creases the propensity to own a car or hold a GA travelcard (weakly significant). In addition, people of higher education were found to be more likely to own a car or car-sharing membership. A possible interpretation of this observation is that while a higher household income allows to invest more in mobility options, professions available for highly-educated workers often require flexible commut475 ing or travel.

For car ownership, not only the level of accessibility, but also the spatial structure of the municipality has a significant effect. While car-ownership is lowest for people both working and living in the centers of larger cities, living or pursuing activities in the fringe of an agglomeration has a similar effect on car-ownership as rural areas. This probably reflects the usually car-centered development of

\footnotetext{
${ }^{10}$ Micro-accessibility as defined in the Swiss standard SN 640 290; level B corresponds to an equivalent of a rail station with frequent long-distance service ( $<10$ min headway per main load direction) in $<750 \mathrm{~m}$ distance or a bus stop with frequent service $(<10 \mathrm{~min}$ headway per main load direction) in the immediate surroundings ( $<300 \mathrm{~m}$ distance).
} 
such municipalities. Given the substantial structural differences among the five isolated cities, the corresponding effect is hard to interpret.

Another interesting observation is that a growing household size has a negative effect on car-ownership and car-sharing membership (although insignificant). For car-ownership, this seemingly contradicts earlier findings that household size has a positive effect on the number of vehicles per household [30, 33. However, in this analysis, the response variable is car availability (i.e. always having a car available) which likely decreases when a car is shared by more than one household member. In turn, car-sharing membership is less likely for larger households given that larger households are more likely to own a private vehicle covering also those use cases, a car-sharing vehicle would have been used for otherwise.

495

With respect to car-sharing membership, it is interesting to note that the distance to the next car-sharing station has no significant effect on the propensity of car-sharing membership (even when included as inverse, quadratic term or dummy variable). This observation may be explained by the dense network of car-sharing stations covering especially those areas, which are well-connected by public transportation. Hence, the distance to a car-sharing station may be confounded with the micro-accessibility of public transportation $(\rho=0.4)$.

Of particular interest is the influence of the latent variables on the propen505 sities to own a given mobility tool. As the correlation between the two latent variables suggests, their effects mostly point into the same direction. Both latent variables have a positive effect on season tickets and car-sharing memberships and a negative effect on car-ownership. This is not surprising given that the variables represent attitudes either against inexpensive car use or for more investments into public transportation or active modes.

An important observation already at this stage is that the effect of the co- 
variates discussed above on car-sharing membership is positively correlated to season ticket ownership, but negatively correlated with car-ownership.

The above notion is supported by an analysis of the correlations of the error terms, i.e. the unobserved effects. In particular, Table 9 shows that there is significant and substantial negative correlation between the error terms of the car-ownership equation and both the public transport subscriptions and the car-sharing membership equation. In turn, there is substantial and significant positive correlation of the error terms between the public transport subscriptions and the car-sharing membership equation. It is interesting to note that the correlations for the GA travelcard have the same sign and significance than for public transportation subscriptions. Hence, a GA travelcard appears to ${ }_{525}$ be an even stronger substitute for car-ownership as may even more likely be complemented by a car-sharing membership than local public transportation subscriptions.

Yet, the substantial negative correlation in both the observed and unobserved 530 effects between car-sharing membership and car-ownership, conceal that $40.2 \%$ of the car-sharing members also own a car (c.f. Table 10). Hence, given the low share of car-sharing members among car-owners, the model results do not account for the fact that to a certain degree, car-sharing is also used as an additional household vehicle. 
Table 9: Correlations in the error terms of the individual equations of the multivariate Probit model.

\begin{tabular}{lrr}
\hline & Cor. & S.e. \\
\hline PT subscription - car & $-0.368^{* * *}(0.024)$ \\
PT subscription - car-sharing & $0.208^{* * *}(0.044)$ \\
PT subscription - GA travelcard & $0.923^{* * *}(0.113)$ \\
car - car-sharing & $-0.357^{* * *}(0.039)$ \\
car - GA travelcard & $-0.313^{* * *}(0.033)$ \\
car-sharing - GA travelcard & $0.186^{* *}(0.054)$ \\
\hline$N$ & \multicolumn{2}{c}{8477} \\
\hline
\end{tabular}

${ }^{*} p<0.05,{ }^{* *} p<0.01,{ }^{* * *} p<0.001$ 


\section{Conclusions}

The modeling approach presented above goes beyond earlier models by jointly addressing four different types of mobility tools and capturing the effect of attitudes on the individual alternatives. As presented in Table 8 , the model reveals that there indeed are significant and substantial correlations in the error terms of the four equations indicating that common unobserved effects are present, even after controlling for transport policy attitudes. Possible examples of such unobserved effects may be lifestyle attributes or the structure of social networks. However, independent of the actual nature of the unobserved effects, this research shows that earlier approaches without joint estimation (e.g. 31) can only provide the direction, but not the magnitude of the effects of the explanatory variables.

Another interesting observation is that there is a significant effect of the latent variables on the choice of all four mobility tools. Although the attitudes to a certain degree have to be considered as endogenous [64, they do explain a substantial share of the choice behavior. Yet, the model may only be used to describe the current situation, but not to predict levels of mobility tool ownership for varying degrees of attitudes 65. It is interesting to note that the effect of the two latent variables is similar for car-sharing membership and GA travelcard ownership in that the PROINFRA variable has no (highly) significant effect and in that the size of the significant effect of the PROFEES variable is similar. This is in contrast to season ticket ownership for which the effect of PROINFRA is significant and positive. Hence, car-sharing members share the idea of an enhanced regulation or taxation of car use, but do not demand higher investments into public transportation. Yet, it is unclear whether this is due to the fact that they already benefit from good conditions for public transportation or whether this reflects a general tendency to lower government spending. Either way, the results of this research show that the effect of individual attitudes should not be neglected when describing mobility tool ownership. 
The results further confirm the important role of accessibilities in shaping travel behavior [66]. Although often described by spatial structure [2, 30, population density [31] or distance to the city center [29], earlier studies have consistently found lower levels of car-ownership and increased use of public transportation for people living in urban centers. However, it was also shown that accessibility (i.e. travel times to attractions) is not the only determinant, but has to be regarded in conjunction with the micro-accessibility (i.e. frequency) of public transportation as well as the spatial structure of the municipality. In particular, the results confirm earlier findings that car-sharing adoption does not depend on densities or accessibilities, but on the micro-accessibility of public transportation [24, 25]. However, the effective distance to the next available car-sharing station has no significant effect. This clearly indicates that station-based carsharing is not used for daily travel, but to complement a public transportation lifestyle.

580

This notion is complemented by an analysis of the observed and unobserved correlations between the four equations which show a clear divide between public transportation and car-sharing on one side and car-ownership on the other side. Yet, the results may also indicate that car-sharing is not only used as supplement to public transportation, but also to a private vehicle (e.g. for occasions in which a second car is needed).

With respect to the general spatial and individual characteristics governing carsharing adoption, this research allows to confirm many results of earlier research. Also here, car-sharing was found to be favored by young and highly educated customers living in small households in an area which is well-connected by public transportation [24, 25]. However, in contrast to earlier findings, a higher household income per capita does not have a significant effect on car-sharing membership.

595 
Moreover, it should be noted that including land-use variables as mere exogenous variables is not accurate given that also the choice of a home location may be in itself affected by preferences for certain mobility tools [67, 68, 69.

This research extends earlier findings by showing that also a strong attitude against car use has a significant and substantial effect on the propensity of becoming a car-sharing member. In addition, the results clarify that car-sharing membership is independent not only from urban density, but also from accessibilities (i.e. travel times). Instead, it is the frequency of available public transport connections, which has a substantial effect on car-sharing membership.

In addition, this is the first approach considering car-sharing as a mobility tool in its own right. Using this approach, it was shown that car-sharing clearly 610 works as supplement to other mobility tools, mostly public transportation. An interesting finding however is that the correlation between car-sharing membership and both public transport subscriptions is on a similar level indicating that the use cases of car-sharing vehicles rather complement than compete with public transportation.

615

A summary of the results is that both car and GA travelcard represent highly flexible mobility tools attracting affluent and frequent travelers. In turn, carsharing appears to be a complement for holders of a season-ticket who sometimes need to travel off the public transport network and (to a lesser extent) for 620 car-owners who occasionally need a second vehicle. 


\section{Acknowledgements}

This research is part of a Swiss National Fund project (National Research Program 71: Managing Energy Consumption, project number 407140_153807) and was supported by the ETH Research Grant ETH-04 15-1. The help of

${ }_{625}$ Nathalie Picard and Michel Bierlaire in designing and implementing the mod-

elling framework is greatly appreciated. We also thank the two anonymous reviewers for their helpful comments. 


\section{References}

[1] S. Le Vine, M. Lee-Gosselin, A. Sivakumar, J. Polak, Design of a StrategicTactical Stated-Choice Survey Methodology Using a Constructed Avatar, Transportation Research Record 2246 (2011) 55-63.

[2] A. Simma, K. W. Axhausen, Structures of commitment in mode use: A comparison of Switzerland, Germany and Great Britain, Transport Policy 8 (4) (2001) 279-288.

[3] H. Becker, F. Ciari, K. W. Axhausen, Comparing car-sharing schemes in Switzerland: User groups and usage patterns, Transportation Research Part A 97 (2017) 17-29.

[4] C. R. Bhat, A multiple discretecontinuous extreme value model: formulation and application to discretionary time-use decisions, Transportation Research Part B 39 (8) (2005) 679-707.

[5] C. R. Bhat, S. Sen, Household vehicle type holdings and usage: an application of the multiple discrete-continuous extreme value (MDCEV) model, Transportation Research Part B 40 (1) (2006) 35-53.

[6] C. R. Bhat, S. Astroza, R. Sidharthan, M. J. B. Alam, W. H. Khushefati, A joint count-continuous model of travel behavior with selection based on a multinomial probit residential density choice model, Transportation Research Part B 68 (2014) 31-51.

[7] C. R. Bhat, A. R. Pinjari, S. K. Dubey, A. S. Hamdi, On accommodating spatial interactions in a Generalized Heterogeneous Data Model (GHDM) of mixed types of dependent variables, Transportation Research Part B 94 (2016) 240-263.

[8] S. A. Shaheen, A. P. Cohen, Carsharing and Personal Vehicle Services: Worldwide Market Developments and Emerging Trends, International Journal of Sustainable Transportation 7 (2013) 5-34. 
[9] P. Muheim, E. Reinhardt, Carsharing: The key to combined mobility, World Transport, Policy \& Practice 5 (3) (1999) 58-71.

[10] C. Lane, PhillyCarShare - First-year social and mobility impacts of carsharing in Philadelphia, Pennsylvania, Transportation Research Record 1927 (2005) 158-166.

[11] E. Martin, S. Shaheen, Greenhouse gas emission impacts of carsharing in North America, Intelligent Transportation Systems 12 (4) (2011) 10741086.

[12] T. D. Chen, K. M. Kockelman, Carsharing's Life-Cycle Impacts on Energy Use and Greenhouse Gas Emission, Transportation Research Part D 47 (2016) 276-284.

[13] A. Millard-Ball, G. Murray, J. t. Schure, C. Fox, J. Burkhardt (Eds.), Car-Sharing: Where and How It Succeeds, Vol. 108 of Transit Cooperative Research Program Report (TCRP), Transportation Research Board, Washington, D.C., 2005.

[14] L. Sioui, C. Morency, M. Trépanier, How Carsharing Affects the Travel Behavior of Households: A Case Study of Montréal, Canada, International Journal of Sustainable Transportation 7 (2013) 52-69.

[15] G. S. Mishra, R. R. Clewlow, P. L. Mokhtarian, K. F. Widaman, The effect of carsharing on vehicle holdings and travel behavior: A propensity score and causal mediation analysis of the San Francisco Bay Area, Research in Transportation Economics 52 (2015) 46-55.

[16] D. Bongart, G. Wilke, Innovation and diffusion of car-sharing for sustainable consumption and production of urban mobility, in: 2nd Conference of the Sustainable Consumption Research Exchange (SCORE!) Network, Brussels, 2008, pp. 61-66. 
[17] F. Ciari, K. W. Axhausen, Choosing carpooling or carsharing as a mode: Swiss stated choice experiments, in: 91st Annual Meeting of the Transportation Research Board, Washington, D.C., 2012.

[18] Swiss Federal Statistical Office (BFS), Ergebnisse des Mikrozensus 2005 zum Verkehrsverhalten, Swiss Federal Statistical Office (BFS), Neuchatel (2006).

[19] Swiss Federal Statistical Office (BFS), Mobilität in der Schweiz - Ergebnisse des Mikrozensus Mobilität und Verkehr 2010, Swiss Federal Statistical Office (BFS), Neuchatel (2012).

[20] S. A. Shaheen, N. D. Chan, H. Micheaux, One-way carsharing's evolution and operator perspectives from the Americas, Transportation 42 (2015) $519-536$.

[21] R. Cervero, A. Golub, B. Nee, City CarShare: Longer-Term Travel Demand and Car Ownership Impacts, Transportation Research Record 1992 (2007) 70-80.

[22] E. Martin, S. Shaheen, The impact of carsharing on public transit and non-motorized travel: An exploration of North American carsharing survey data, Energies 4 (11) (2011) 2094-2114.

[23] J. Burkhardt, A. Millard-Ball, Who Is Attracted to Carsharing?, Transportation Research Record 1986 (2006) 98-105.

[24] C. Celsor, A. Millard-Ball, Where Does Carsharing Work?: Using Geographic Information Systems to Assess Market Potential, Transportation Research Record 1992 (2007) 61-69.

[25] T. Stillwater, P. L. Mokhtarian, S. A. Shaheen, Carsharing and the Built Environment, Transportation Research Record 2110 (2009) 27-34.

[26] G. de Jong, J. Fox, A. Daly, M. Pieters, R. Smit, A comparison of car ownership models, Transport Reviews 24 (4) (2004) 379-408. 
[27] G. C. de Jong, R. Kitamura, A review of household dynamic vehicle ownership models: Holdings models versus transactions models, Transportation 36 (6) (2009) 733-743.

[28] S. Anowar, N. Eluru, L. F. Miranda-Moreno, A Transnational Alternative Modeling Approaches Used for Examining Automobile Ownership: A Comprehensive Review, Transport Reviews 34 (4) (2014) 441-473.

[29] T. Yamamoto, Comparative analysis of household car, motorcycle and bicycle ownership between Osaka metropolitan area, Japan and Kuala Lumpur, Malaysia, Transportation 36 (3) (2009) 351-366.

[30] D. M. Scott, K. W. Axhausen, Household mobility tool ownership: modeling interactions between cars and season tickets, Transportation 33 (4) (2006) 311-328.

[31] M. Kowald, B. Kieser, N. Mathys, A. Justen, Determinants of mobility resource ownership in Switzerland: changes between 2000 and 2010, Transportation (2016) 1-23.

[32] R. Tanner, D. Bolduc, The Multiple Discrete-Continuous Extreme Value Model (MDCEV) with fixed costs, Procedia - Social and Behavioural Sciences 111 (2014) 390-399.

[33] D. Potoglou, Y. O. Susilo, A Comparison of Disaggregate Car Ownership Models, Transportation Research Record 6 (2076) (2008) 97-105.

[34] W. H. Greene, Econometric analysis, 7th Edition, Boston, MA: Pearson, 2012.

[35] R. Gulati, M. C. Higgins, Which ties matter when? The contingent effects of interorganizational partnerships on IPO success, Strategic Management Journal 24 (2) (2003) 127-144.

[36] S. P. Jenkins, L. Cappellari, P. Lynn, A. Jäckle, E. Sala, Patterns of consent: Evidence from a general household survey, Journal of the Royal Statistical Society, Series A 169 (4) (2006) 701-722. 
[37] P. Mokhtarian, W. Tang, Trivariate probit models of prepurchase/purchase shopping channel choice: clothing purchases in Northern California, in: S. Hess, A. Daly (Eds.), Choice Modelling, Edward Elgar, London, 2013, Ch. 12, pp. 243-273.

[41] Bundesamt für Raumentwicklung, Verkehrserschliessung in der Schweiz Webpage (last accessed 14.02.2017) (2017).

URL

II

[43] A. Loder, K. W. Axhausen, Mobility tools and usage: The role of accessibility and transport related attitudes in Switzerland, Arbeitsberichte Verkehrs- und Raumplanung 1217, IVT, ETH Zurich, Zurich (2016). 
[44] Mobility Car-Sharing, Mobility stations, Webpage (last accessed

[45] J. C. Hayton, D. G. Allen, V. Scarpello, Factor retention decisions in exploratory factor analysis: A tutorial on parallel analysis, Organizational https://www.mobility.ch/en/private-customers/ mobility-stations/ Research Methods 7 (2) (2004) 191-205.

[46] D. Bolduc, R. Alvarez-Daziano, On estimation of hybrid choice models, Choice Modelling: The State-of-the-Art and the State-of-Practice, Proceedings from the Inaugural International Choice Modelling Conference (2010) 259-287.

[47] S. Raveau, R. Alvarez-Daziano, Y. Yanez, D. Bolduc, J. de Dios Ortuzar, Sequential and simultaneous estimation of hybrid discrete choice models: Some new findings, Transportation Research Record 2156 (2010) 131-139.

[48] B. Schmid, S. Schmutz, K. W. Axhausen, Exploring the choice between instore and online shopping, in: 23rd EIRASS conference on Recent Advances in Retailing and Service Strategies, Edinburgh, 2016.

[49] C. Li, Little's test of missing completely at random, The Stata Journal 13 (4) (2013) 795-809.

[50] Stata Press, Structural equation modeling reference manual, version 13 Edition, Stata Press, Texas, 2013.

[51] A. Daly, S. Hess, B. Patruni, D. Potoglou, C. Rohr, Using ordered attitudinal indicators in a latent variable choice model: A study of the impact of security on rail travel behaviour, Transportation 39 (2) (2012) 267-297.

[52] K. G. Jöreskog, A. S. Goldberger, Estimation of a model with multiple indicators and multiple causes of a single latent variable, Journal of the American Statistical Association 70 (351a) (1975) 631-639. 
[53] K. A. Bollen, Structural Equations With Latent Variables, John Wiley \& Sons, New York, 1989.

[54] T. F. Golob, Structural equation modeling for travel behavior research, Transportation Research Part B 37 (1) (2003) 1-25.

[55] J. J. Heckman, The Common Structure of Statistical Models of Truncation, Sample Selection and Limited Dependent Variables and a Simple Estimator for Such Models, Annals of Economic and Social Measurement 5 (4) (1976) 475-492.

[56] K. Van der Straeten, A. Trannoy, N. Picard, C. Hagneré, L'importance des incitations financières dans l'obtention d'un emploi est-elle surestimée?, Économie \& prévision 160 (4) (2003) 49-78.

[57] D. Deadman, Z. MacDonald, Offenders as Victims of Crime? An Investigation into the Relationship between Criminal Behaviour and Victimization, Journal of the Royal Statistical Society, Series A 167 (1) (2004) 53-67.

805 [58] S. Morris, The impact of obesity on employment, Labour Economics 14 (3) (2007) 413-433.

[59] A. Bryson, L. Cappellari, C. Lucifora, Does union membership really reduce job satisfaction?, British Journal of Industrial Relations 42 (3) (2004) 439459.

[60] R. Carrasco, Binary Choice With Binary Endogenous Regressors in Panel Data, Journal of Business \& Economic Statistics 19 (4) (2001) 385-394.

[61] R. Paleti, C. Bhat, R. Pendyala, Integrated Model of Residential Location, Work Location, Vehicle Ownership, and Commute Tour Characteristics, Transportation Research Record 2382 (2013) 162-172.

815 [62] L. Cappellari, S. P. Jenkins, Calculation of multivariate normal probabilities by simulation, with applications to maximum simulated likelihood estimation, Stata Journal 6 (2) (2006) 156-189. 
[63] K. E. Train, Discrete Choice Methods with Simulation, Cambridge, MA: Cambridge University Press, 2003.

${ }_{820}^{62}$ [64] R. Dobson, F. Dunbar, C. J. Smith, D. Reibstein, C. Lovelock, Structural models for the analysis of traveler attitude-behavior relationships, Transportation 7 (4) (1978) 351-363.

[65] C. G. Chorus, M. Kroesen, On the (im-)possibility of deriving transport policy implications from hybrid choice models, Transport Policy 36 (2014) $217-222$.

[66] R. Ewing, R. Cervero, Travel and the Built Environment, Journal of the American Planning Association 76 (3) (2010) 265-294.

[67] A. Pinjari, N. Eluru, C. Bhat, R. Pendyala, E. Spissu, Joint model of choice of residential neighborhood and bicycle ownership: accounting for selfselection and unobserved heterogeneity, Transportation Research Record 2082 (2008) 17-26.

[68] B. van Wee, Self-Selection: A Key to a Better Understanding of Location Choices, Travel Behaviour and Transport Externalities?, Transport Reviews 29 (3) (2009) 279-292.

${ }_{835}$ [69] X. Cao, P. L. Mokhtarian, S. L. Handy, Examining the Impacts of Residential Self-Selection on Travel Behaviour: A Focus on Empirical Findings, Transport Reviews 29 (3) (2009) 359-395. 


\section{Appendix}

Table 10: Distribution of mobility tool ownership ( $N=6939$ - drivers license holders only).

\begin{tabular}{l|rrrr}
\hline & Car & PT subscription & GA travelcard & Car-sharing \\
\hline$n$ & 5581 & 1266 & 496 & 199 \\
Base-rate & $80.4 \%$ & $18.2 \%$ & $7.1 \%$ & $2.9 \%$ \\
\hline Subsets & & & & \\
Car-owners & & $13.0 \%$ & $4.9 \%$ & $1.4 \%$ \\
PT subscription holders & $57.4 \%$ & & $39.2 \%$ & $7.7 \%$ \\
GA travelcard holders & $51.6 \%$ & & & $10.5 \%$ \\
Car-sharing members & $40.2 \%$ & $48.7 \%$ & $26.1 \%$ & \\
\hline
\end{tabular}




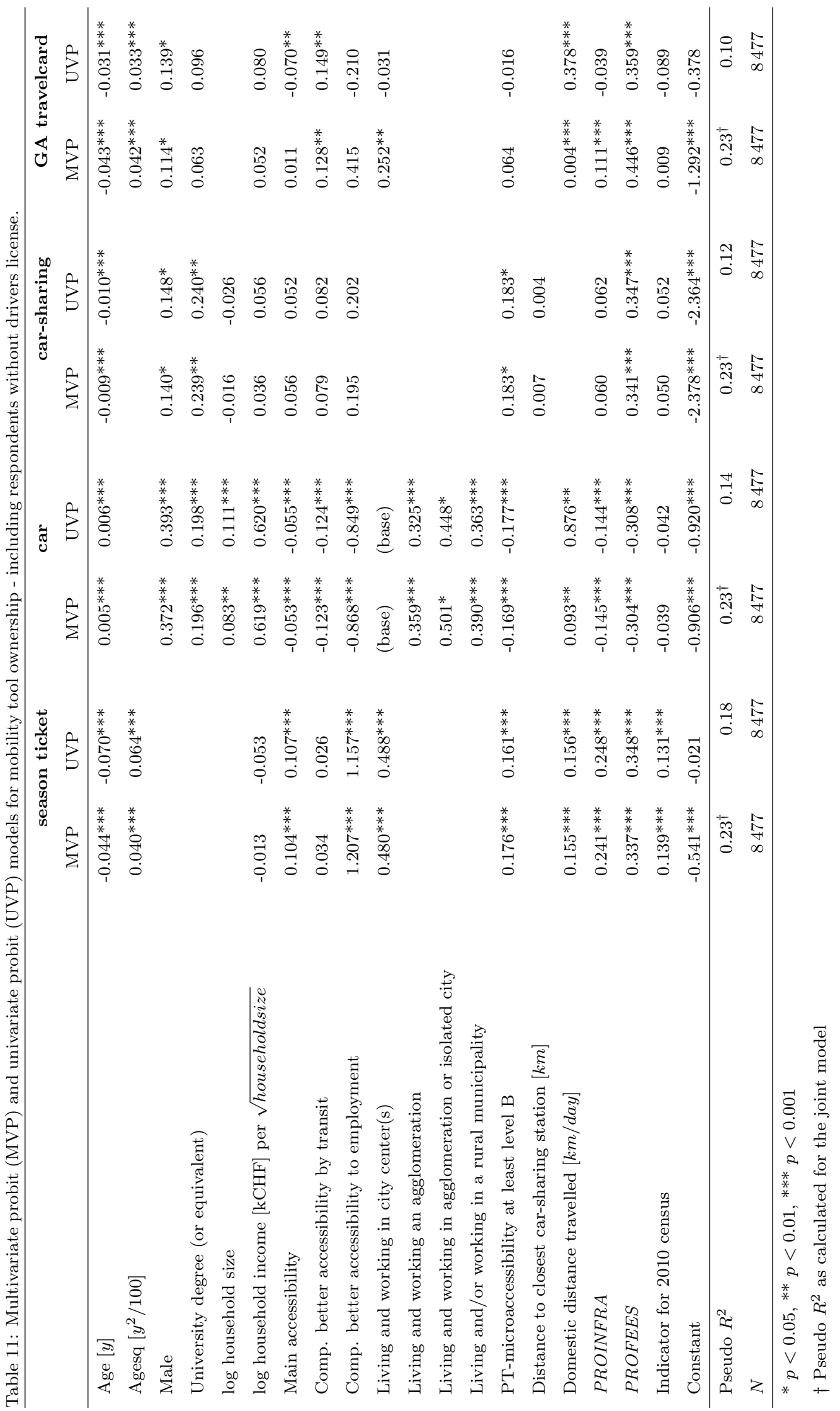

